\title{
GLOW DISCHARGE PLASMA TREATMENT ON NONWOVEN FABRICS FOR MEDICAL APPLICATION
}

\author{
S. Inbakumar ${ }^{1,2, *}$ and P. M. Andavan ${ }^{3}$ \\ ${ }^{1}$ Department of R\&D, Bharathiar University, Coimbatore, Tamilnadu. \\ ${ }^{2}$ Faculty of Physics, Department of Science \& Humanities, Kumaraguru College of Technology, \\ Coimbatore, Tamilnadu, India. \\ ${ }^{3}$ Department of Physics, Government Arts College, Coimbatore, Tamilnadu, India \\ *E-mail: inbakumar.s.sci@kct.ac.in
}

\begin{abstract}
In this paper, glow discharge plasma operating in air atmosphere has been used to improve the surface hydrophilic and antibacterial properties of the polyester non-woven fabric. The wicking height results show that the surface hydrophilic property of the fabric samples is greatly improved with plasma treatment. The analysis of SEM shows that the surface roughness of the treated fabric samples increases due to etching in plasma processing. The analysis of FTIR and XPS indicate that oxygen-containing and nitrogen-containing polar functional groups and addition that copper is embedded on the polyester surface in plasma processing. Plasma-treated samples will use to good padding cloth and dressing cloth.
\end{abstract}

Keywords: Polyester nonwoven fabric, Surface modification, Glow discharge, Hydrophilic property, Medical application

(C) RASĀYAN. All rights reserved

\section{INTRODUCTION}

Polyester (PES) and Polypropylene (PP) nonwoven fabrics are widely used in baby diapers, biomedical textiles, geotextiles, battery separators, oil adsorbents, filtration media, flame retardant ${ }^{1,2}$ etc. In most instances, the nonwovens for the above-mentioned applications need to be more wettable by water or other water-based liquids. However, the low surface energy of PES and PP makes them naturally hydrophobic, and their wettability is to be increased by a hydrophilic surface treatment. Traditionally, the surface treatment is performed by using aqueous solutions of surfactants either by spraying or by lick-up. The use of surfactants, however, introduces some problems such as toxicity, stain and cleans up problems and additional cost. Moreover, the surfactants tend to be washed off upon frequent exposure to liquids. Plasma treatment is commonly used for surface activation and modification of different materials including textiles. Plasma is an outwards neutral, partially ionized gas, the composition of which depends on the gas used in the formation of plasma. Gas molecules are ionized in an electric field through electron impacts, and the ionized, highly reactive species, such as ions, electrons, and radicals, modify the surface of the substrate material. The textile applications of plasma include, for example, flame retardant finishing $^{3,7}$, adhesion ${ }^{9,10,13}$, wettability and hydrophobicity ${ }^{4,5,7}$, dyeability enhancement ${ }^{4}$, and antimicrobial properties $^{8}$. Some of these treatments can be conducted using common gas plasma, but some of them utilize specific chemicals in the formation of plasma.

\section{EXPERIMENTAL}

\section{Glow discharge plasma treatment}

The plasma system is consists of a cylindrical plasma chamber (length $50 \mathrm{~cm}$, diameter $25 \mathrm{~cm}$ ), a vacuum pumping system and a DC power supply. Glow discharge plasma is generated between two copper electrodes. One electrode is permanently fixed; the other one is movable. Before putting the fabric sample into the system, the chamber is cleaned with distilled water and acetone. After this, a nonwoven fabric sample is fixed in a sample holder and introduced into the plasma chamber. For all experiments 
performed in this paper, the nonwoven fabric is placed parallel with the electrodes at $1 \mathrm{~cm}$ from the cathode. The pressure inside the plasma chamber is measured using a pirani gauge and during plasma processing, the $0.3 \mathrm{mbar}$ pressure is maintained by using a needle valve. After reaching the required pressure in the plasma chamber, the DC power supply is switched on and maintained $350 \mathrm{~V}$ throughout the experiments.

\section{Wicking measurements}

A nonwoven fabric strip is hanging vertically with the lower end dipped in a water-dye liquor and as a result, a spontaneous wicking arises due to capillary forces. The blue coloration of the dye solution on the nonwoven fabric clearly indicates that capillary rise height and a ruler (in $\mathrm{mm}$ ) assembled beside the nonwoven strip enables the height measurements ${ }^{14}$.

\section{Weight loss and SEM experiments}

Some degradation reactions could be initiated on the nonwoven surfaces by glow discharge plasma due to ion and electron bombardment. As a result, weight loss of the nonwoven fabrics changes of the nonwoven surfaces can occur. In order to observe the etching effect of the low-pressure glow discharge on the nonwoven fabrics, weight loss and scanning electron microscopy experiments are performed. The weight loss percentage is calculated according to the following equation:

$$
W_{\text {loss }}(\%)=\frac{W_{u t}-W_{p t}}{W_{u t}} * 100
$$

where $\mathrm{W}_{\mathrm{ut}}$ and $\mathrm{W}_{\mathrm{pt}}$ are the weight of the untreated and plasma-treated samples respectively.

\section{FTIR and XPS measurements}

Fourier-transform infrared spectroscopy (FTIR) is performed on a Bruker Vertex 70 spectrometer purged with dry, $\mathrm{CO}_{2}$ free air. The FTIR spectra are recorded using a liquid nitrogen cooled MCT (MercuryCadmium-Telluride) detector with a resolution of $4 \mathrm{~cm}^{-1}$ and 32 scans are taken for each measurement. XPS analysis is used to determine the chemical changes on the nonwoven fabric surfaces introduced by plasma treatment. XPS measurements are carried out on a VG Escalab 220 XL system (Thermo Fisher Scientific - USA), using non-monochromatic $\mathrm{Mg} \mathrm{K}_{\mathrm{a}}$-radiation $(h n=1253.6 \mathrm{eV})$ operated at $15 \mathrm{kV}$ and 20 $\mathrm{mA}$.

\section{Hydrophilic Analysis}

\section{RESULTS AND DISCUSSION}

For surfaces with a more open structure, like non-woven and woven fabrics, contact angle measurements are difficult due to the roughness and porous structure of the fabrics. Therefore, in this work, the hydrophilic behavior of the untreated and plasma-treated nonwoven samples are verified by performing wicking rate measurements based on the standard DIN 53923.

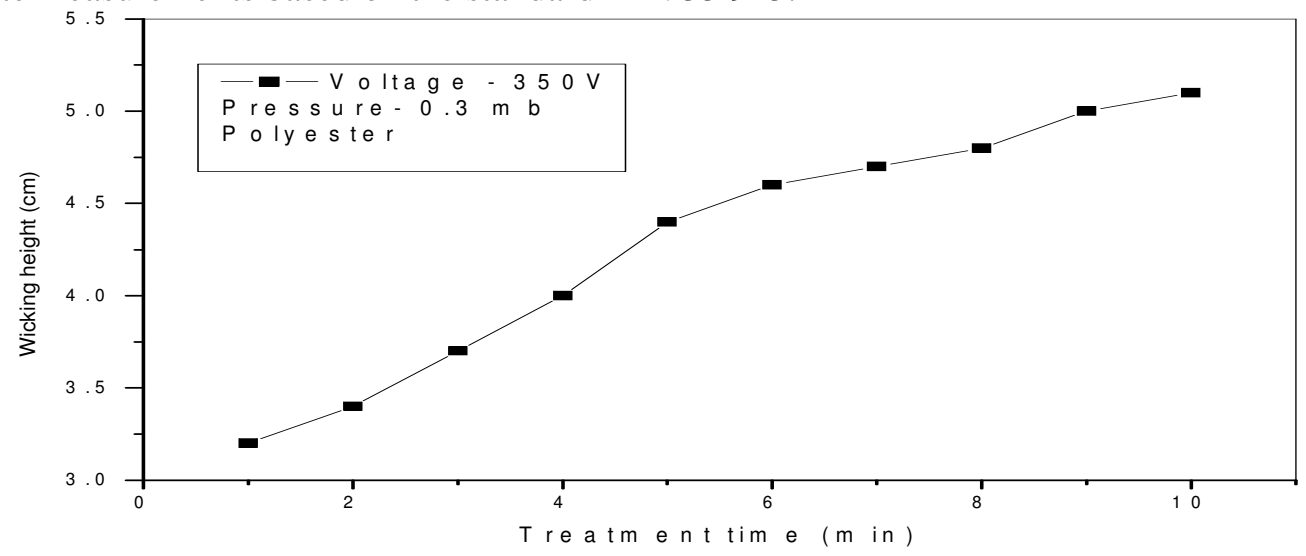

Fig.-1: Plasma treatment time vs wicking height 
It can be observed from the Fig.-1 that all nonwoven samples treated with plasma had a significant improvement in their wickability when compared with the nontreated nonwoven sample. The wettability improved due to the upper surface of the polymers being scratched by a plasma process and due to radicals of the air plasma contents.

\section{Atomic concentration analysis}

From the FTIR Fig.-2, most pronounced changes between the untreated and treated nonwoven samples after air plasma treatment is in the range $2700-3500 \mathrm{~cm}^{-1}$ and $1000=1700 \mathrm{~cm}^{-1}$. The peaks attributed to $\mathrm{OH}$ and $\mathrm{NH}$ vibrations, aliphatic $\mathrm{CH}$ groups, and metal carbonyl groups. Around $830 \mathrm{~cm}^{-1} \mathrm{CCl}$ groups and $940 \mathrm{~cm}^{-1}$ corresponds to olefinic $\mathrm{CH}$ wag. The region of $1000-1300 \mathrm{~cm}^{-1}$ corresponds to C-O bonds. The presence of these polar groups strongly contributes to increasing the hydrophilic nature of the fabric surface.

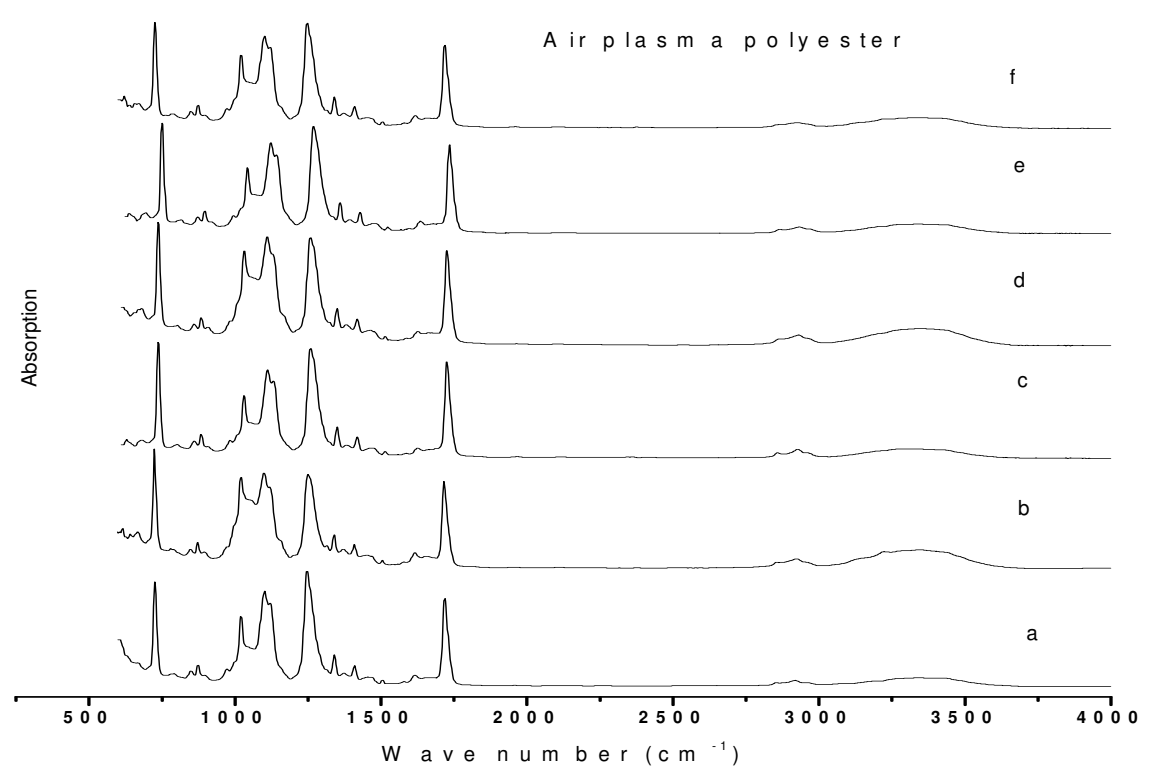

Fig.-2: FTIR Spectrum for Plasma treated and untreated nonwoven fabrics

A low-pressure glow discharge in the air can generate a wide range of active species including atomic oxygen, ozone, nitrogen oxides, neutral and metastable molecules, radicals and ultraviolet radiation. Air plasma increases the surface energy of polymers and textiles by introducing oxygen-containing polar groups onto the polymer surface. Atomic oxygen is believed to be the main reactive species responsible for this oxygen inclusion. Atomic oxygen is formed because of the dissociation of $\mathrm{O}_{2}$ molecules by electron impact. However, also excitation and dissociation of nitrogen molecules lead to a number of additional reaction paths that can produce additional atomic oxygen ${ }^{10}$. To evaluate what functional groups were formed by plasma treatment, the atomic composition of the untreated and of plasma treated samples was determined by XPS. Plasma treated nonwoven polyester fabric's carbon atomic concentration is 69.841 it is the highest percentage of the fabric but the ratio of the percentage is decreased after the plasma treatment from 81.975 to 69.841 . And calcium is not presented. The oxygen atomic concentration is increased from 15.033 to 21.298 due to plasma treatment. The elevated degree of oxygenation of the little crystalline sample shows a better chemical reactivity of the sample with plasma. It emerges that the reaction intermediates (mainly the radicals) were comparatively more mobile in the polymer matrix having a lesser crystalline fraction and, hence, are usually to react more without difficulty with the oxygen ions in the plasma ${ }^{15}$.

Silicon and chlorine atomic concentration are slightly increased after the plasma treatment. Also, copper elements are presented its concentration is 3.188 which is the highest concentration of the silicon, 
RASĀYAN J. Chem.

Vol. 10 | No. 4 |1226-1231 | October - December | 2017

chlorine, and fluorine. The copper particles are etched from the copper electrode and deposited on the surface of the fabric. Copper atomic concentration is increasing with increasing plasma treatment time due to deposition concentration is greater for the greater treatment time.

Table-1: Atomic concentration of Plasma treated and untreated nonwoven PES fabrics

\begin{tabular}{l|l|l|l|l}
\hline \multirow{3}{*}{ Peak } & \multicolumn{3}{|l|}{ Nonwoven polyester } & Plasma treated Nonwoven \\
\cline { 2 - 5 } & $\begin{array}{l}\text { Binding energy } \\
\text { Centre (eV) }\end{array}$ & AT\% & $\begin{array}{l}\text { Binding energy } \\
\text { Centre (eV) }\end{array}$ & AT\% \\
\hline O1s & 532 & 15.033 & 531.8 & 21.298 \\
Ca 2p & 347.6 & 1.741 & ---- & --- \\
C 1s & 285 & 81.975 & 285 & 69.841 \\
Cl 2p & 198.2 & 0.318 & 198.9 & 2.89 \\
Si 2p & 102 & 0.933 & 103.1 & 1.298 \\
Cu 2p3 & ---- & ----- & 933.4 & 3.188 \\
F 1s & ----- & ---- & 685 & 1.485 \\
\hline
\end{tabular}
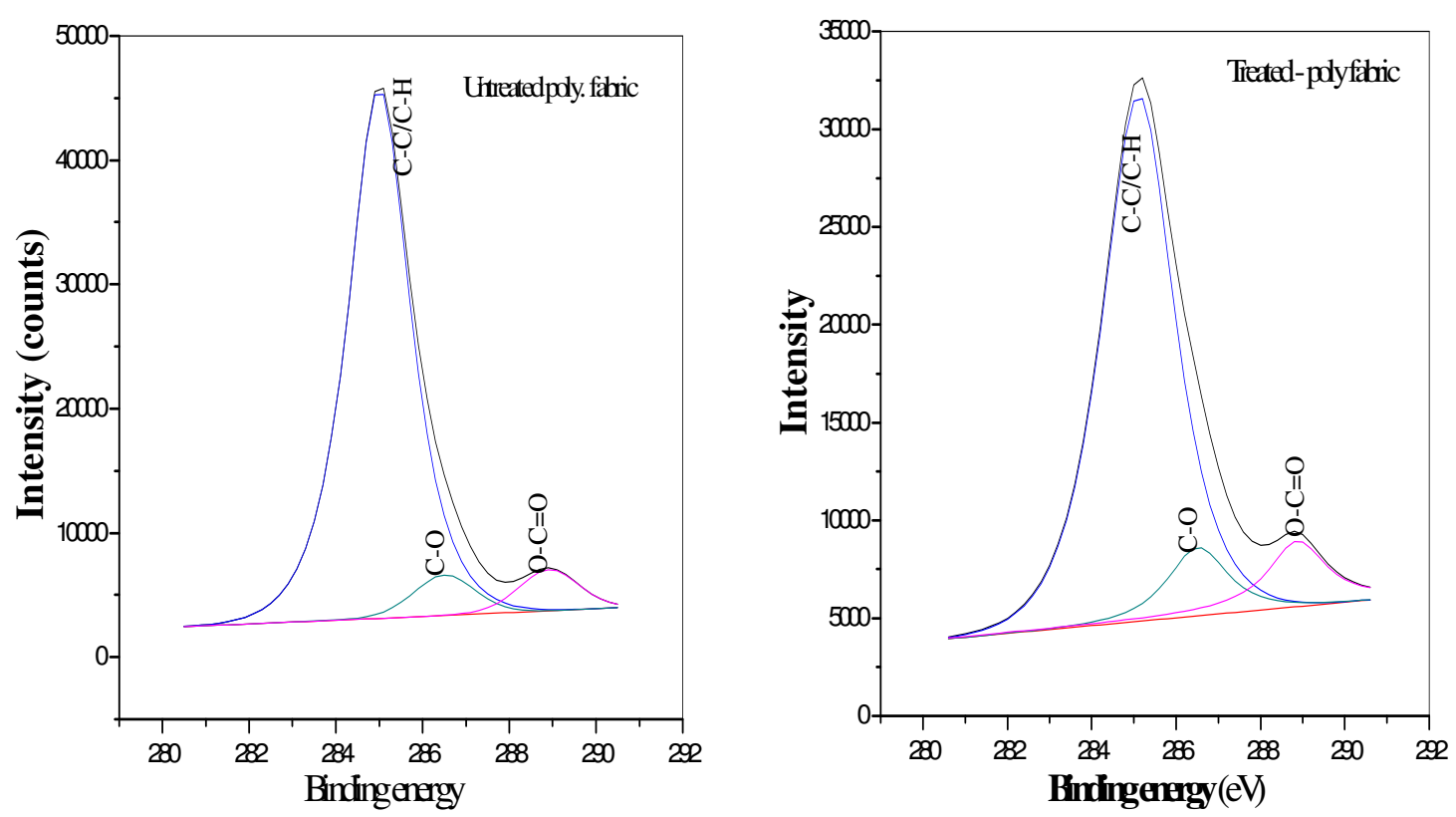

Fig.3: XPS Spectrum of Plasma treated and untreated nonwoven PES fabrics

\section{Weight loss and SEM Analysis}

One of the plasma- acting mechanisms is based on etching as a consequence of the impact of the gas plasma species on the polymer surface. This mechanism increases surface roughness and contributes to better surface wettability. It is possible to quantify the extent of etching caused by a plasma treatment by simple weight loss analysis. Weight loss highly depends on the polymer structure and the reactivity of the gas used for the plasma treatment ${ }^{8}$.Degradation of the Polymeric surface leads to a small modification of the surface morphology by increasing the surface roughness.

Figure-5 shows photographs obtained through electron scanning electron microscope of treated samples fibres (a b\&c), as well as the nontreated one (d). It is clear that the treated samples suffered morphological alteration on their surface, with the formation of fissures and pores, due to plasma etching and plasma particle attack on the sample surface by plasma treatment. The roughness of the fabrics is used in paint due to enriching the adhesion properties. And also will use the padding and dressing cloths. 
RASĀYAN J. Chem.

Vol. 10 | No. 4 |1226-1231 | October - December | 2017

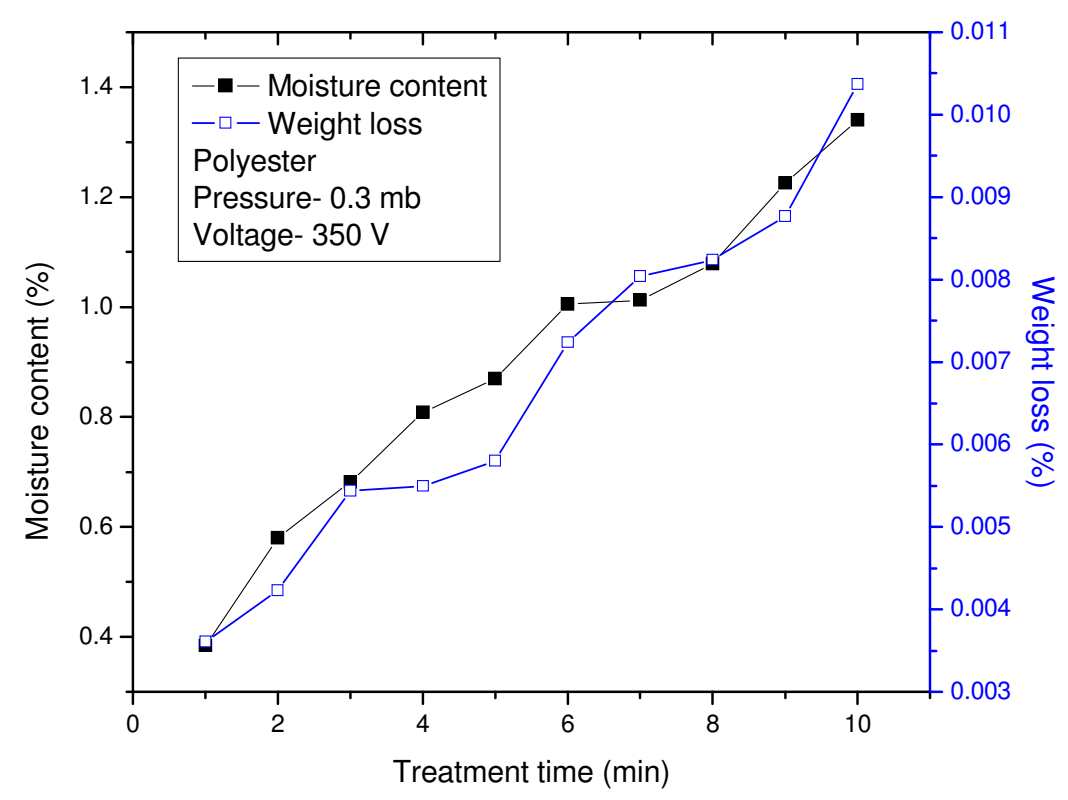

Fig.-4: Plasma treatment time vs moisture content and weight loss
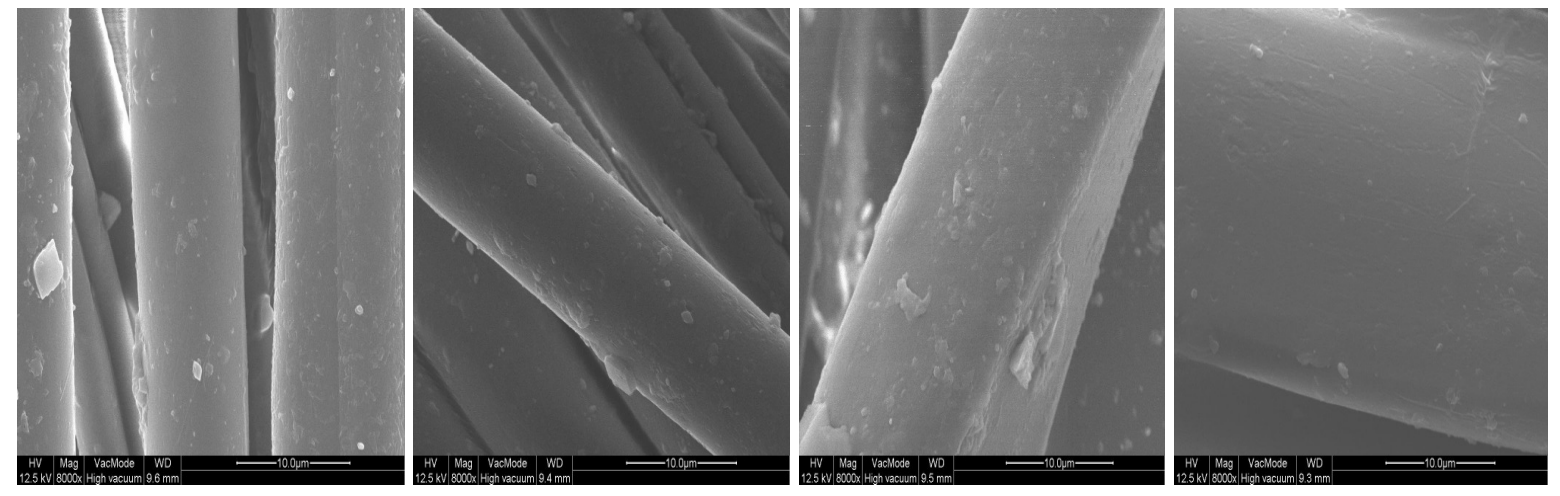

Fig.-5: SEM images of Plasma treated and untreated PES fabrics

\section{CONCLUSION}

Plasma treatment greatly enhances polar contributions to solid surface energy values and it is indicated that one of the most important plasma mechanism is surface activation due to the formation of polar groups as it can be seen from the FTIR and XPS observations. A rougher fabric surface is important in the conventional aqueous textile finishing and dyeing processing because of a higher rate of liquid uptake. Plasma treated fabric surface will be used as good padding and dressing materials due to the electrode materials are embedded on treated samples because normally all metals are having good antibacterial properties.

\section{REFERENCES}

1. Sheng Zhang, A. Richard Horrocks, Progress in Polymer Science., 28, 11, 1517(2003)

2. B.F.Yousif, S.T.W.Lau, S. McWilliam, Tribology International., 43(1-2), 503(2010)

3. F. Caiazzo, P. Canonico, R. Nigro and V. Tagliaferri, J. Mater. Process Tecnol., 58, 96(1996).

4. N. Dumitrascu, C. Borcia, Surface \& Coatings Technology., 201, 1117(2006).

5. CS. Zhang, P. Chen, D. Liu, BC .Wang, W. Li, XT. Kang, Surface and Interface Analysis.,41, 187(2009) .

6. D. Jocic, S. Vilchez, T. Topalovic, R. Molina, A. Navarro, P. Jovancic, M.R. Julia, P. Erra, Journal of Applied Polymer Science., 97, 2204(2005). 
7. C.S. Ren, D.Z. Wang, Y.N. Wang, Journal of Materials Processing Technology., 206,216(2008).

8. D. Hegemann, H. Brunner and C. Oehr, NuclInstrum Meth Phy Res Sect B-Beam Interact Atoms ., 208, 281(2003).

9. F. Leroux, C. Campagne, A.Perwuelz, L.Gengembre, Applied Surface Science., 254, 3902,10(2008).

10. D. Hegemann, H Brunner and C. Oehr, NuclInstrum Meth Phy Res Sect B-Beam InteractAtoms., 208,281(2003).

11. Jahagirdar, Yasmin Srivastava, Journal of Applied Polymer science., 82, 292(2001).

12. S. Inbakumar, Rino Morent, Nathalie De Geyter, Tim Desmet, A Anukaliani, Peter Dubruel, Christophe Leys, Cellulose., 17(2), 417(2010).I

13. N. Inagaki, K.Narushim, N. Tuchida, K. Miyazaki, Journal of Applied Polymer science B., 42, 3727(2004).

14. S. Inbakumar and A.Anukaliani, Composite Interfaces., 19(3-4),209(2012).

15. R. L. Clough, in: Encyclopedia of Polymer Science and Engineering, J. I. Kroschwitz(Ed.)., Vol. 6. Wiley, New York, NY, 23(1988).

[RJC-1928/2017] 